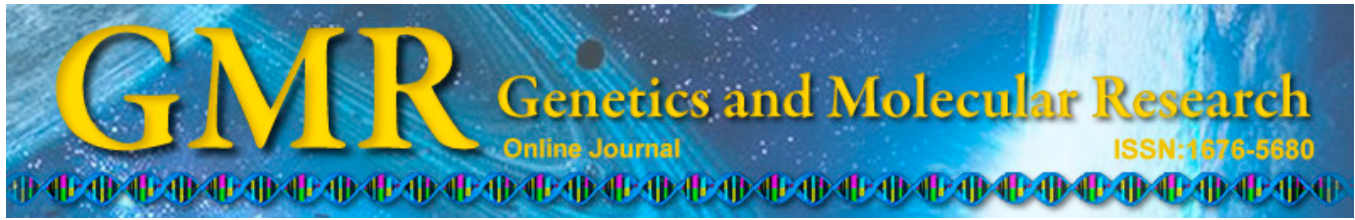

\title{
Inhibition of adipogenic differentiation of bone marrow mesenchymal stem cells by erythropoietin via activating ERK and P38 MAPK
}

\author{
G.X. Liu*, J.C. Zhu*, X.Y. Chen, A.Z. Zhu, C.C. Liu, Q. Lai and S.T. Chen \\ Hematology Institute of Ji'nan University, Guangzhou City, \\ Guangdong Province, China \\ *These authors contributed equally to this study. \\ Corresponding author: S.T. Chen \\ E-mail: liugexiu_lgx@163.com
}

Genet. Mol. Res. 14 (2): 6968-6977 (2015)

Received August 6, 2014

Accepted January 22, 2015

Published June 26, 2015

DOI http://dx.doi.org/10.4238/2015.June.26.5

\begin{abstract}
We examined whether erythropoietin (EPO) can inhibit adipogenic differentiation of mesenchymal stem cells (MSCs) in the mouse bone marrow and its underlying mechanism. We separated and extracted mouse bone marrow MSCs and induced adipogenic differentiation using 3-isobutyl-1-methylxanthine, insulin, and dexamethasone. Different concentrations of EPO were added to the cells and observed by Oil Red O staining on the 20th day to quantitatively analyze the degree of cell differentiation. mRNA expression levels of peroxysome proliferator-activated receptor $\gamma$ (PPAR $\gamma$ ), CCAAT enhancer binding protein $\alpha$, and adiponectin were analyzed by real-time quantitative polymerase chain reaction, and the activity of PPAR $\gamma$, extracellular signal-regulated kinase (ERK), and p38 mitogen-activated protein kinase (p38 MAPK) were determined by western blotting. EPO significantly inhibited adipogenic differentiation of MSCs after 20 days and reduced absorbance values by Oil Red $\mathrm{O}$ staining without affecting proliferation
\end{abstract}


activity. EPO downregulated the mRNA expression of PPAR $\gamma$, CCAAT enhancer binding protein $\alpha$, fatty acid binding protein 4 , and adiponectin during adipogenesis and increased protein phosphorylation of ERK, p38 MAPK, and PPAR $\gamma$ during differentiation. EPO downregulated the mRNA expression of PPAR $\gamma$, CCAAT enhancer binding protein $\alpha$, fatty acid binding protein 4 , and adiponectin by increasing protein phosphorylation of ERK, p38 MAPK, and PPAR $\gamma$ during differentiation, which inhibited adipogenic differentiation of MSCs.

Key words: Differentiation; Erythropoietin; Mesenchymal stem cell; Proliferation; Signaling pathways

\section{INTRODUCTION}

In mammals, erythropoietin (EPO) is a glycoprotein produced by the kidney and liver. Under low oxygen conditions, EPO binds to its receptor (EPO-R) to promote the proliferation of erythroid progenitor cells and differentiation into mature red blood cells to increase the number of red blood cells in circulation (Szenajch et al., 2010). Currently, EPO is mainly used for anemia treatment after surgery, chronic renal failure, and chemotherapy. Recent studies have shown that EPO-R is widely distributed in non-hematopoietic tissues such as the spleen, lung, brain, and heart muscle cells, indicating that it has a variety of non-hematopoietic activities (Digicaylioglu et al., 1995; Grimm et al., 2002). The role of EPO in non-hematopoietic cells includes promotion of endothelial cell proliferation (Anagnostou et al., 1994), protection of myocardial injury caused by myocardial infarction (Kagaya et al., 2012), inhibition of ventricular remodeling induced by angiotensin II (Zhang et al., 2009), and improvement of the recovery of damaged nerve cells (Sirén et al., 2001). In addition, EPO can inhibit inflammatory factors and promote fracture healing (Garcia et al., 2011) by reducing the expression of nuclear factor- $\mathrm{\kappa B}$. Hojman et al. (2009) demonstrated that EPO can inhibit the weight gain of mice induced by a high-fat diet, while mice lacking EPO-R expression are more likely to gain fat and develop insulin resistance. In addition, cellular experiments showed that EPO can inhibit the differentiation of 3T3-L1 preadipocytes (Teng et al., 2011), but the effect of EPO on bone marrow mesenchymal stem cells (MSCs) remains unknown. In this study, we examined whether EPO could inhibit adipogenic differentiation of mouse bone marrow MSCs, and the potential mechanism of this action is discussed.

\section{MATERIAL AND METHODS}

\section{Experimental materials}

Male 6-week-old mice were obtained from the Animal Laboratory of Sun Yat-Sen University (Guangdong, China). Dulbecco's modified Eagle medium (DMEM) and trypsin were obtained from Hyclone (Logan, UT, USA). Recombinant human erythropoietin was purchased from 3SBio (Shenyang, China). Fetal calf serum, dexamethasone, 3-isobutyl1-methylxanthine, insulin, and Oil Red O solution were obtained from Gibco (Grand Island, NY, USA). The Alizarin Red S kit was from Genmed (Shanghai, China). Thiazolyl blue was from Kehao (Xi'an, China). RNAiso Reagent, the cDNA kit, and the reverse transcription- 
polymerase chain reaction (PCR) kit were from Toyobo (Osaka, Japan). GAPDH polyclonal antibody and ECL chemiluminescent solution were from Lianke Bio. Rabbit-anti-mouse peroxisome proliferator-activated receptor $\gamma$ (PPAR $\gamma$ ), phosphorylated (p)-PPAR $\gamma$, extracellular signal-regulated kinase 42 (ERK42), p-ERK42, ERK44, p-ERK44, p38 mitogen-activated protein kinase (p38 MAPK), and p-p38 MAPK antibody were from Cell Signaling Technology (Danvers, MA, USA). Horseradish peroxidase anti-mouse II and horseradish peroxidase goat-anti-rabbit II were from Santa Cruz Biotechnology (Santa Cruz, CA, USA).

\section{Procedures}

\section{Separation and extraction of mouse bone marrow MSCS}

Six-week-old male Kunming mice were sacrificed by vertebra dislocation. Mice were immersed for $2 \mathrm{~min}$ in $75 \%$ ethanol, both sides of the femur were separated, and the muscle and bone myofascial tissue attached to the bone surface were removed. The femur was disconnected and DMEM complete medium with a $1-\mathrm{mL}$ injector was used to wash marrow cavity repeatedly until the marrow cavity turned pale. Collected cells were transferred to $15-\mathrm{mL}$ centrifuge tubes and centrifuged at $800 \mathrm{rpm}$ for $5 \mathrm{~min}$. The supernatant was removed and the culture solution was added to re-suspend the cells, which were then inoculated at approximately $5 \times 10^{6}$ cells into a $25-\mathrm{cm}^{2}$ culture bottle. The cells were cultivated in a $5 \% \mathrm{CO}_{2}$ incubator at $37^{\circ} \mathrm{C}$. The solution was exchanged to remove suspended cells and impurities after $24 \mathrm{~h}$, and then changed every 3 days. Cell growth was observed under a microscope and cells were passaged when $80 \%$ confluence was observed. MSCs were examined following the 3rd passage using Alizarin Red S staining for osteogenic differentiation and Oil Red O staining for adipogenic differentiation.

\section{Induction of MSC adipogenic differentiation}

The 3rd-passage cells were induced to differentiate 2 days after complete confluence. Cells were cultivated in DMEM complete medium containing 0.5 M 3-isobutyl-1-methylxanthine, $5 \mathrm{mg} / \mathrm{L}$ insulin, and $1 \mu \mathrm{M}$ dexamethasone for 3 days, and then the medium was exchanged to DMEM complete medium containing $5 \mathrm{mg} / \mathrm{L}$ insulin for 1 day. This was repeated for 5 cycles while adding different concentrations of EPO.

\section{Oil Red $O$ staining}

Cells were washed 3 times with phosphate-buffered saline 20 days after inducing differentiation, fixed with $4 \%$ paraformaldehyde for $30 \mathrm{~min}$, stained with Oil Red O, and incubated for $60 \mathrm{~min}$ at room temperature. The cells were then rinsed 3 times with phosphate-buffered saline and the formation of lipid droplets was observed under a microscope. Finally, Oil Red O was extracted using isopropanol and absorbance was measured at $520 \mathrm{~nm}$ after $5 \mathrm{~min}$.

\section{Determination of cell proliferation activity using MTT}

MSCs were inoculated into 96 -well plates at a density of $5 \times 10^{4} /$ well and cultivated with adipogenic differentiation solution containing different concentrations of EPO $(0,0.1,1$, 
5, $10 \mathrm{U} / \mathrm{mL}$ ) for $72 \mathrm{~h}$. Next, $20 \mu \mathrm{L} 5 \mathrm{~g} / \mathrm{L}$ 3-(4,5-dimethylthiazol-2-yl)-2,5 tetrazolium bromide (MTT) was added per well and the plates were incubated at $37^{\circ} \mathrm{C}$ for $4 \mathrm{~h}$, after which $50 \mu \mathrm{L}$ dimethyl sulfoxide was added per well. The plate was shaken for 5 min and absorbance was measured at $490 \mathrm{~nm}$ using a microplate reader.

\section{Detection of gene expression of adipogenic differentiation by real-time quantitative PCR}

All groups of adipogenic differentiation cells were collected and total RNA was extracted using Trizol reagent. To examine the differentiation of fat cells, mRNA expression of adipogenic differentiation was detected by real-time quantitative PCR after cDNA was synthesized through reverse transcription using the primers shown in Table 1. PCR conditions were as follows: 45 cycles of pre-denaturation at $93^{\circ} \mathrm{C}$ for $3 \mathrm{~min}$, denaturation at $93^{\circ} \mathrm{C}$ for $1 \mathrm{~min}$, annealing at $60^{\circ} \mathrm{C}$ for $30 \mathrm{~s}$, extension at $72^{\circ} \mathrm{C}$ for $1 \mathrm{~min}$, and final extension at $72^{\circ} \mathrm{C}$ for $10 \mathrm{~min}$. The $2^{-\Delta \Delta \mathrm{Ct}}$ was calculated for each group to determine relative mRNA transcript levels of PPAR $\gamma$, CCAAT/ enhancer-binding protein $\alpha(C / E B P \alpha)$, fatty acid binding protein $4(F A B P 4)$, and adiponectin.

Table 1. Primer sequences of detected genes in reverse transcription-PCR analysis.

\begin{tabular}{ll}
\hline Name & Primer sequence (5'-3') \\
\hline GAPDH & Forward: AGGTCGGTGTGAACGGATTTG \\
& Reverse: AGGTCGGTGTGAACGGATTTG \\
C/EBPa & Forward: GGAAGACCACTCGCATTCCTT \\
& Reverse: GTAATCAGCAACCATTGGGTCA \\
FABP4 & Forward: CAAGAACAGCAACGAGTACCG \\
& Reverse: GTCACTGGTCAACTCCAGCAC \\
adiponectin & Forward: AAGGTGAAGAGCATCATAACCCT \\
& Reverse: TCACGCCTTTCATAACACATTCC \\
& Forward: ACCACTATGATGGCTCCACT \\
& Reverse: GGTGAAGAGCATAGCCTTGT \\
\hline
\end{tabular}

\section{Western blotting}

All groups of adipogenic differentiation cells were collected, rinsed 2 times with phosphate-buffered saline, lysed using cell lysis buffer for $30 \mathrm{~min}$, centrifuged at $4{ }^{\circ} \mathrm{C}$ and $12,000 \mathrm{rpm}$ for $10 \mathrm{~min}$, and tested to determine protein content using a BCA Protein Assay Kit. Next, $30 \mu \mathrm{g}$ protein sample was boiled to denature the protein after adding loading buffer and samples were separated by $10 \%$ sodium dodecyl sulfate-polyacrylamide gel electrophoresis. Samples were transferred to a polyvinylidene fluoride membrane and blocked with 5\% skim milk at room temperature for $1 \mathrm{~h}$. Primary antibody was added and the membrane was incubated overnight at $4^{\circ} \mathrm{C}$, and washed with Tris-buffered saline containing Tween 20 three times. Secondary antibody was added and incubated for $1 \mathrm{~h}$ and the membrane was washed with Tris-buffered saline containing Tween 20 three times. Membranes were developed using electrochemiluminescence solution.

\section{Statistical analysis}

Results are reported as means \pm standard deviation and data were analyzed using the SPSS 13.0 software (SPSS, Inc., Chicago, IL, USA). Groups were compared using one-way analysis of variance and differences were considered to be statistically significant when $\mathrm{P}<0.05$. 


\section{RESULTS}

\section{Separation and cultivation of mouse bone marrow MSCs}

After MSCs were inoculated for $24 \mathrm{~h}$, most cells were suspended, but a few cells had slowly adhered to the wall. Proliferation rate increased after 3-4 days, and confluence was reached after approximately one week. Bone marrow MSCs were separated and purified using a routine adherent method. The $3 \mathrm{rd}$ passage was monomorphic and fusiform and proliferation was active. The 4th passage showed that cells can be differentiated to osteoblasts and fat cells through adipogenic and osteoplastic differentiation (Figure 1A-D).
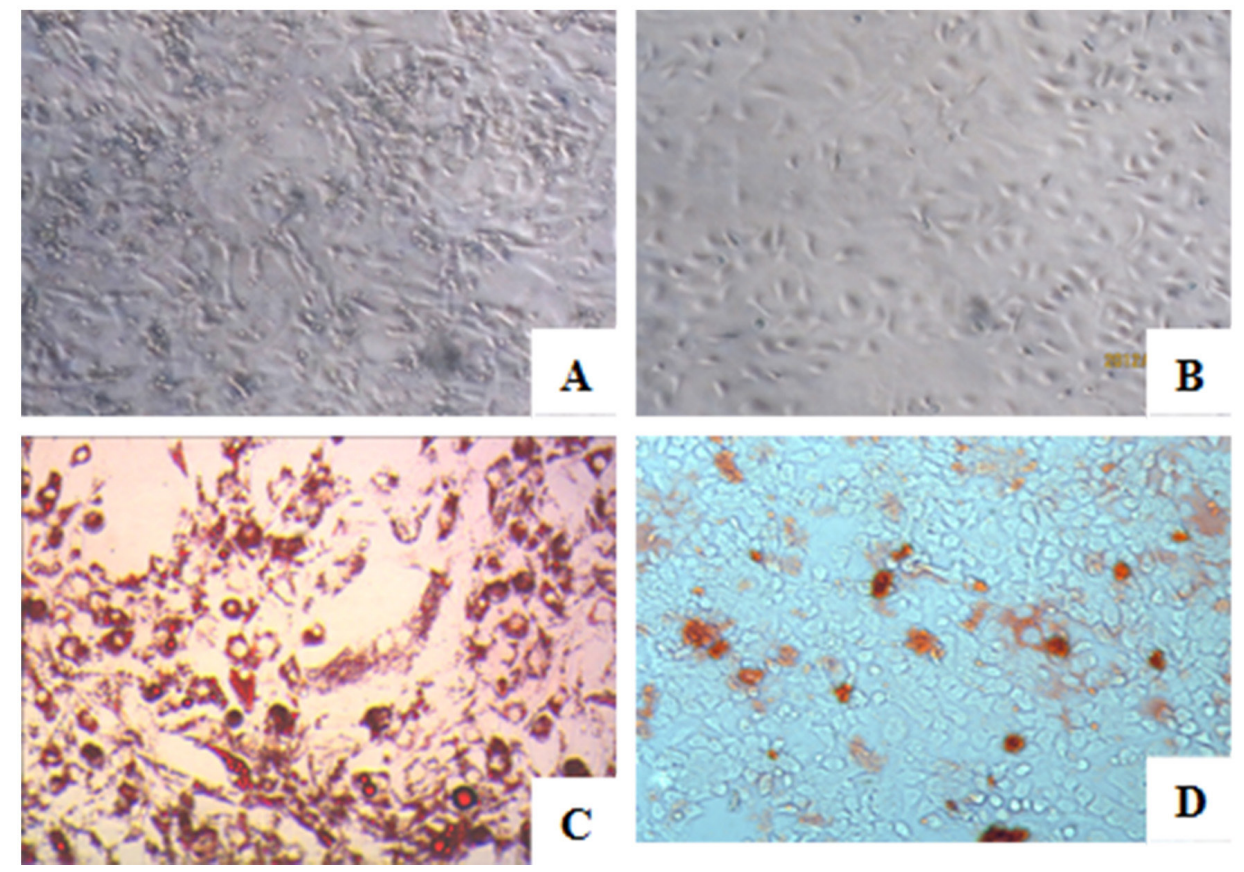

Figure 1. MSCs isolated from mouse bone marrow (200X). A: Primary cells; B: Fourth generation cells; C: Oil Red O staining after adipogenic induction; D: Alizarin red staining after osteogenic inducting differentiation.

\section{Effect of EPO on MSC adipogenic differentiation}

Difference concentrations of EPO $(0,0.1,1,5,10 \mathrm{U} / \mathrm{mL})$ were added during induction to detect the effect of EPO on MSC adipogenic differentiation. The degree of differentiation was evaluated by Oil Red O staining after 20 days. EPO inhibited MSC adipogenesis and the stained lipid droplets in MSCs dramatically decreased as EPO concentration increased (Figure 2a A-E). The concentration showed a negative correlation with optical density value after extracting Oil Red $\mathrm{O}$ by isopropanol (Figure $2 \mathrm{a} \mathrm{E}$ ). In addition, 5 and $10 \mathrm{U} / \mathrm{mL}$ EPO significantly inhibited MSC adipogenic differentiation and reduced A after extraction with Oil Red O (67 and $42 \%$, respectively, $\mathrm{P}<0.05$ ). Based on these results, we selected 5 and $10 \mathrm{U} / \mathrm{mL}$ EPO for subsequent experiments. 

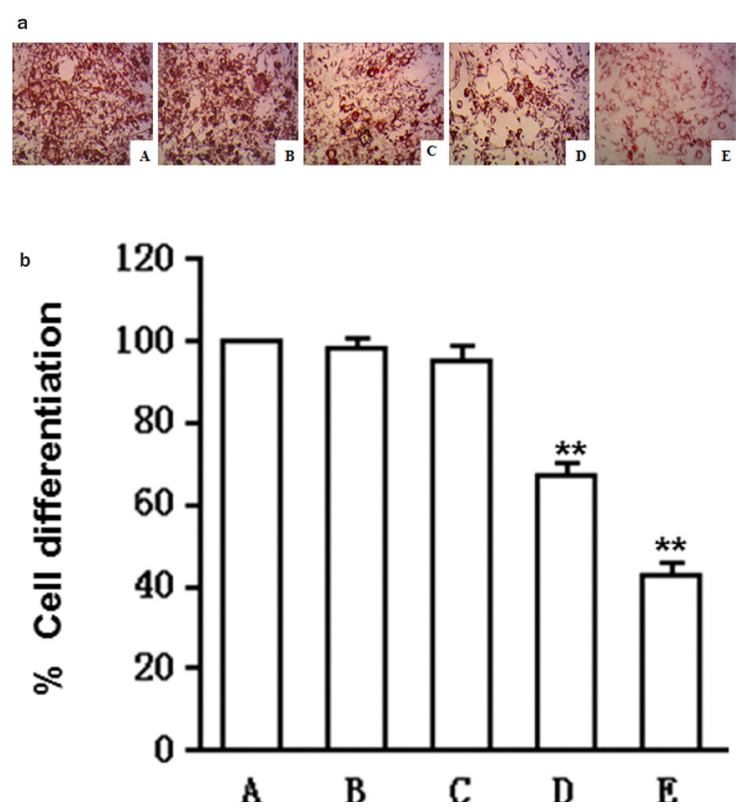

Figure 2. Oil Red $\mathrm{O}$ staining and quantification after adipogenic induction of differentiation for 20 days. a) Oil Red O staining (200X); b) quantification of Oil Red O staining in differentiated MSCs is presented as percentage relative to MSC culture without EPO. (A: EPO 0 U/mL, B: EPO $0.1 \mathrm{U} / \mathrm{mL}, \mathrm{C}$ : EPO $1 \mathrm{U} / \mathrm{mL}$, D: EPO 5 U/mL, E: EPO $10 \mathrm{U} / \mathrm{mL}$ means \pm standard deviation. $\mathrm{N}=5 .{ }^{* *} \mathrm{P}<0.05 v s$ A group).

\section{Effect of EPO on MSC proliferation}

Induction solution was added to converged MSCs showing adipogenic differentiation and $\mathrm{EPO}$ was added at different concentration $(0,0.1,1,5,10 \mathrm{U} / \mathrm{mL})$ to determine its cytotoxicity. Cells were continuously observed for 3 days and evaluated using the MTT method. The results showed that EPO did not affect MSC proliferation (Figure 3).

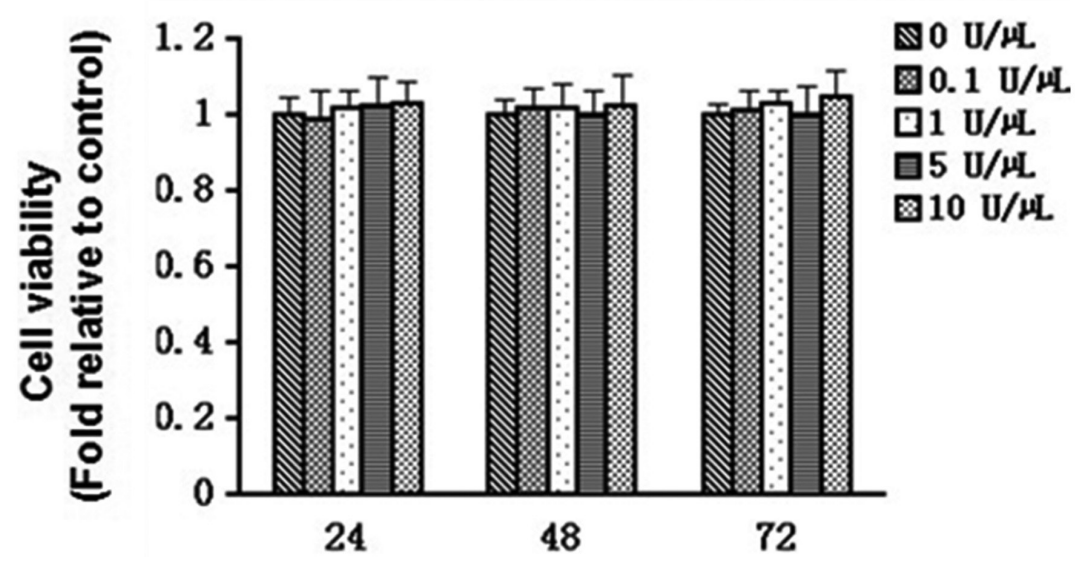

Figure 3. Effects of EPO at different concentrations on the proliferation of MSCs. Means \pm standard deviation. $N=5$. 


\section{Effect of EPO on mRNA expression of adipogenesis-related genes}

EPO was added at 5 and $10 \mathrm{U} / \mathrm{mL}$ during MSC adipogenic differentiation and the expression of adipogenesis-related genes were observed on the 14th day. We found that EPO reduced the mRNA expression of $P P A R \gamma, C / E B P \alpha, F A B P 4$, and adiponectin during adipogenesis. The inhibition rates in the presence of $5 \mathrm{U} / \mathrm{mL}$ EPO were, respectively, 33, 85, 63, and $84 \%$, while these values for $10 \mathrm{U} / \mathrm{mL}$ EPO were, respectively, $39,75,22$, and $77 \%$. The differences were significant $(\mathrm{P}<0.05)$ (Figure 4).
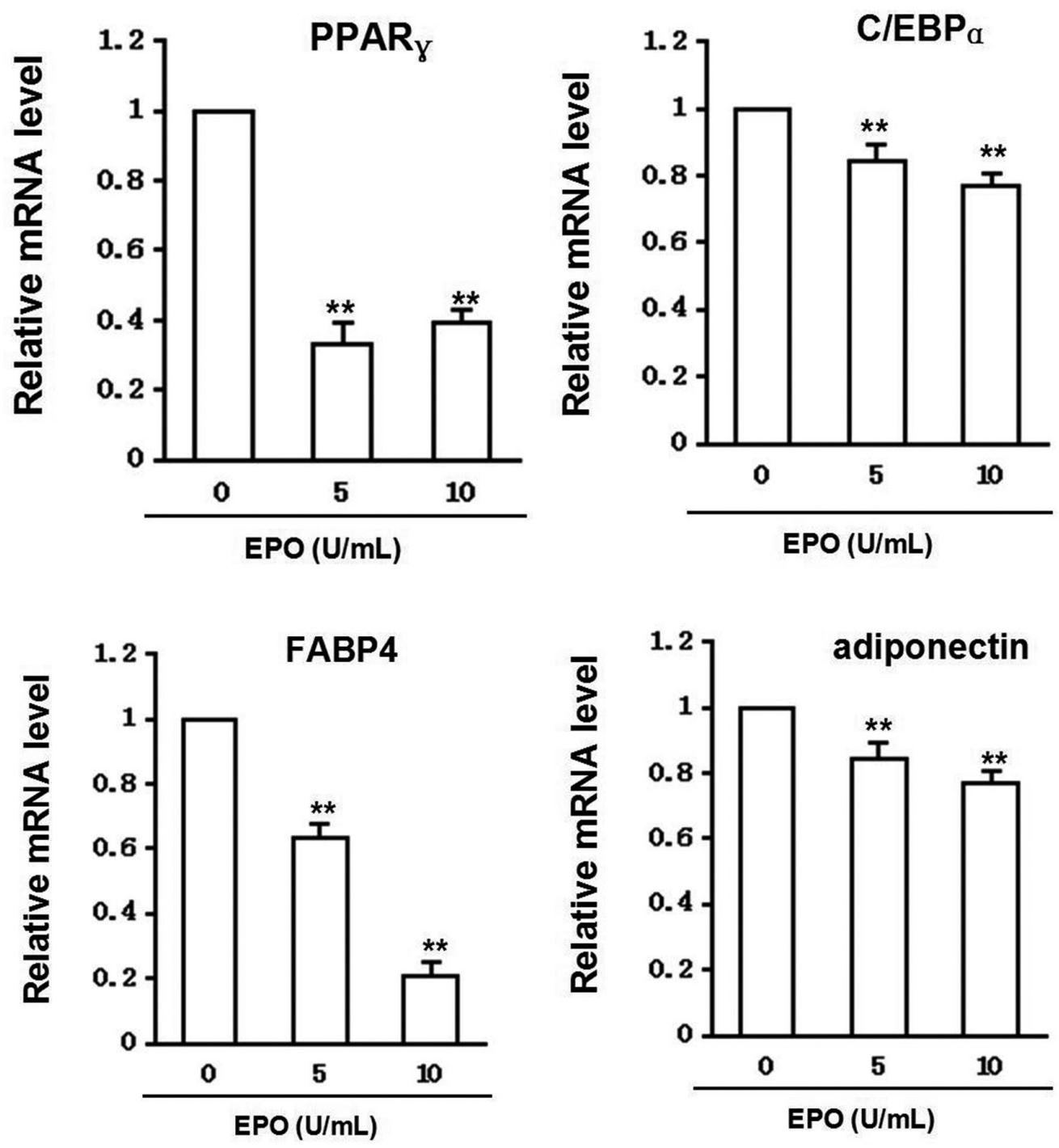

Figure 4. Relative $P P A R \gamma, C / E B P \alpha, F A B P 4$, and adiponectin mRNA levels in MSCs without and with EPO treatment $(0,5,10 \mathrm{U} / \mathrm{mL})$ during differentiation (day 14). Means \pm standard deviation. $\mathrm{N}=5$. $* * \mathrm{P}<0.05$ vs $0 \mathrm{U} /$ $\mathrm{mL}$ EPO group. 


\section{Effect of EPO on ERK and p38 MAPK during MSC adipogenic differentiation}

The phosphorylation activity of ERK42, ERK44, and p38 MAPK were increased after adding 5 and $10 \mathrm{U} / \mathrm{mL}$ EPO during MSC adipogenic differentiation. Phosphorylation of PPAR $\gamma$ increased, but total PPAR $\gamma$ expression was decreased, as shown in Figure 5.

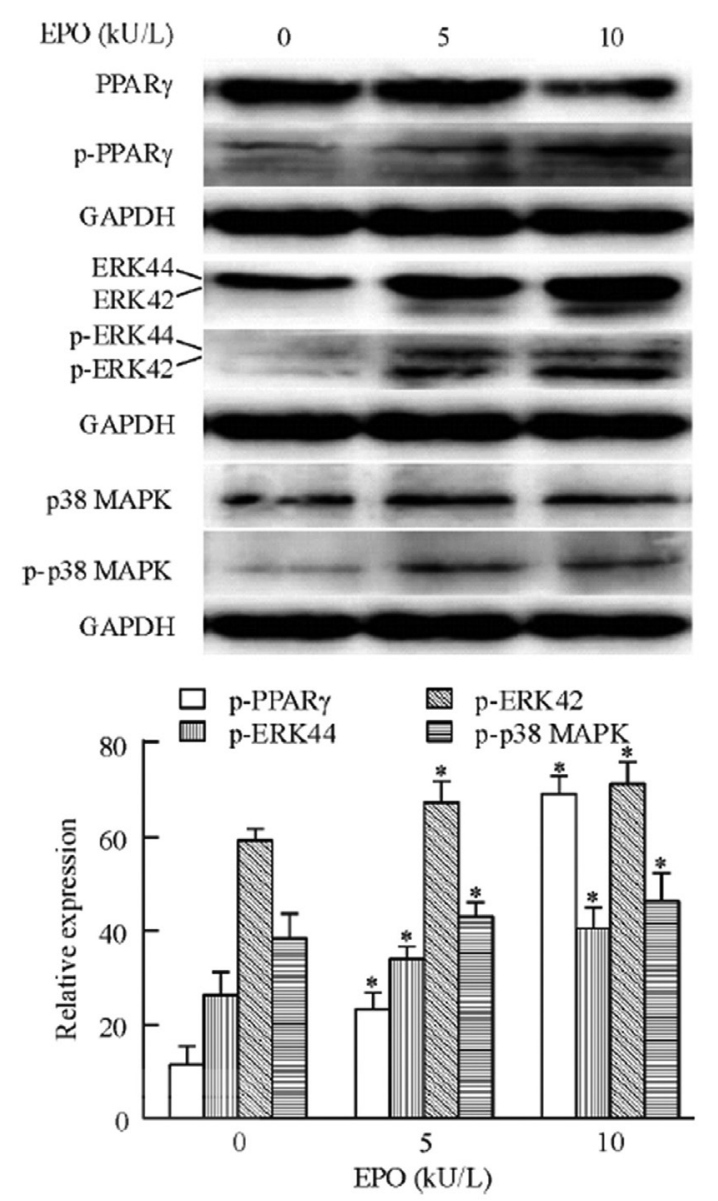

Figure 5. Effect of EPO (5 and $10 \mathrm{U} / \mathrm{mL}$ ) on the expression and phosphorylation of ERK42, ERK44, p38 MAPK, and PPAR $\gamma$. Means \pm standard deviation. $\mathrm{N}=5$. $* \mathrm{P}<0.05$ vs $0 \mathrm{U} / \mathrm{mL}$ EPO.

\section{DISCUSSION}

Bone marrow MSCs are also known as bone marrow stromal cells, which constitute a hematopoietic microenvironment to regulate hemopoietic physiology with hematopoietic stem cells and hemopoietic progenitor cells (McGee et al., 2012). MSCs show multi-directional differentiation potential; they can differentiate into osteoblasts, fat cells, and cartilage cells, among others, in the bone marrow cavity. Naveiras et al. (2009) demonstrated that fat cells in the bone marrow can negatively regulate hematopoietic stem cells. The presence of a 
number of fat cells in the bone marrow can inhibit hematopoietic reconstruction of hematopoietic stem cells after transplantation, while inhibition of mouse marrow fat after chemotherapy can promote hematopoietic recovery (Zhu et al., 2013). In contrast, chronic blood loss in premenopausal women can stimulate marrow hematopoiesis, while marrow fat diseases such as osteoporosis typically develop in postmenopausal women (Gurevitch et al., 1999), indicating that marrow hematopoiesis in the body may also respond to the bone marrow microenvironment. EPO may also participate in the regulation of the bone marrow microenvironment as the most important cell factor promoting differentiation and maturation of red blood cells. Studies have confirmed that EPO can directly promote osteogenesis differentiation of MSCs by binding to the EPO receptor expressed on the MSC surface (Shiozawa et al., 2010), while and osteogenesis differentiation and adipogenic differentiation of MSCs are regulation processes that inhibit and balance each other. Thus, EPO may inhibit the adipogenic differentiation of bone marrow MSCs.

We found that EPO inhibited adipogenic differentiation of bone marrow MSCs based on Oil Red O staining and quantitative analysis. The inhibition effect of 5 and $10 \mathrm{U} / \mathrm{mL}$ EPO was statistically significant. Therefore, we tested the cytotoxic effect of EPO on MSCs cultured in adipogenic differentiation-inducing solution. The results revealed that EPO had no effect on MSC proliferation, and thus EPO had no direct cytotoxic effect on MSCs during adipogenic differentiation.

MSC adipogenic differentiation is a process accompanied by expression of various transcription factors and specific genes in fat cells (Cristancho and Lazar, 2011). To verify the effect of EPO on MSC adipogenic differentiation, we analyzed the expression level of various adipogenic genes. PPAR $\gamma$ and $\mathrm{C} / \mathrm{EBP} \alpha$ are the most crucial transcription factors in adipogenic differentiation, and their synergistic action regulates the expression of various specific factors during this process (Wu et al., 1999), while late FABP4 and adiponectin are specifically expressed by fat cells later in differentiation (Lefterova and Lazar, 2009). Fluorescence quantitative PCR results showed that EPO significantly inhibited the mRNA expression of $P P A R \gamma, C /$ $E B P \alpha, F A B P 4$, and adiponectin.

The MAPK signal pathway participates in all stages of adipogenesis, and ERK and p38 MAPK regulate cell clonal proliferation before differentiation. In addition, ERK and p38 MAPK are essential for initiating the differentiation of preadipocytes, but they must be absent when fat cells are maturing, which may be because PPAR $\gamma$ is a substrate for EPK function. ERK phosphorylation increases PPAR $\gamma$ phosphorylation and leads to decreased activity (Hu et al., 1996; Camp and Tafuri, 1997). In contrast, ERK and p38 MAPK are downstream signaling molecules of the EPO receptor, and thus EPO may function through this signaling pathway. PPAR $\gamma$ phosphorylation increased because MSCs cultured in the presence of EPO upregulated the phosphorylation activity of ERK42, ERK44, and p38 MAPK during differentiation, but total PPAR $\gamma$ decreased. This indicates that EPO regulates adipogenic differentiation by inducing PPAR $\gamma$ phosphorylation by ERK and p38 MAPK.

Our results indicated that EPO downregulates the mRNA expression of PPAR,$C /$ $E B P \alpha, F A B P 4$, and adiponectin by reducing PPAR $\gamma$ activity through MAPK and thus inhibits adipogenic differentiation of MSCs. By examining the effect of EPO on bone marrow MSC adipogenic differentiation, we can further increase the understanding of the interactions between marrow hematopoiesis and the marrow microenvironment to build an experimental and theoretical basis for treating bone marrow failure, bone marrow adipogenesis, and other diseases. 


\section{ACKNOWLEDGMENTS}

Research funded by the Natural Science Foundation of China (\#81270568) and the Science Project of Guangdong Province (\#2012B031800474).

\section{REFERENCES}

Anagnostou A, Liu Z, Steiner M, Chin K, et al. (1994). Erythropoietin receptor mRNA expression in human endothelial cells. Proc. Natl. Acad. Sci. U. S. A. 91: 3 974-3978.

Camp HS and Tafuri SR (1997). Regulation of peroxisome proliferator-activated receptor gamma activity by mitogenactivated protein kinase. J. Biol. Chem. 272: 10811-10816.

Cristancho AG and Lazar MA (2011). Forming functional fat: a growing understanding of adipocyte differentiation. Nat. Rev. Mol. Cell. Biol. 12: 722-734.

Digicaylioglu M, Bichet S, Marti HH, Wenger RH, et al. (1995). Localization of specific erythropoietin binding sites in defined areas of the mouse brain. Proc. Natl. Sci. U. S. A. 92: 3717-3720.

Garcia P, Speidel V, Scheuer C, Laschke MW, et al. (2011). Low dose erythropoietin stimulates bone healing in mice. $J$. Orthop. Res. 29: 165-172.

Grimm C, Wenzel A, Groszer M, Mayser H, et al. (2002). HIF-1-induced erythropoietin in the hypoxic retinaprotects against light-induced retinal degeneration. Nat. Med. 8: 718-724.

Gurevitch O, Prigozhina TB, Pugatsch T and Slavin S (1999). Transplantation of allogeneic or xenogeneic bone marrow within the donor stromal microenvironment. Transplantation 68: 1362-1368.

$\mathrm{Hu}$ E, Kim JB, Sarraf P and Spiegelman BM (1996). Inhibition of adipogenesis through MAP kinase-mediated phosphorylation of PPARgamma. Science 274: 2100-2103.

Hojman P, Brolin C, Gissel H, Brandt C, et al. (2009). Erythropoietin over-expression protects against diet-induced obesity in mice through increased fat oxidation in muscles. PLoS One 4: e5894.

Kagaya Y, Asaumi Y, Wang W, Takeda M, et al. (2012). Current perspectives on protective roles of erythropoietin in cardiovascular system: erythropoietin receptor as a novel therapeutic target. Tohoku J. Exp. Med. 227: 83-91.

Lefterova MI and Lazar MA (2009). New developments in adipogenesis. Trends Endocrinol. Metab. 20: 107-114.

McGee SJ, Havens AM, Shiozawa Y, Jung Y, et al. (2012). Effects of erythropoietin on the bone microenvironment. Growth Factors 30: 22-28.

Naveiras O, Nardi V, Wenzel PL, Hauschka PV, et al. (2009). Bone-marrow adipocytes as negative regulators of the haematopoietic microenvironment. Nature 460: 259-263.

Shiozawa Y, Jung Y, Ziegler AM, Pedersen EA, et al. (2010). Erythropoietin couples hematopoiesis with bone formation. PLoS One 5: e10853.

Sirén AL, Fratelli M, Brines M, Boemans C, et al. (2001). Erythropoietin prevents neuronal apoptosis after cerebral ischemia and metabolic stress. Proc. Natl. Acad. Sci. U. S. A. 98: 4044-4049.

Szenajch J, Wcislo G, Jeong JY, Szczylik C, et al. (2010). The role of erythropoietin and its receptor in growth, survival and therapeutic response of human tumor cells from clinic to bench - a critical review. Biochim. Biophys. Acta 1806: 82-95.

Teng R, Gavrilova O, Suzuki N, Chanturiya T, et al. (2011). Disrupted erythropoietin signalling promotes obesity and alters hypothalamus proopiomelanocortin production. Nat. Commun. 2: 520.

Wu Z, Rosen ED, Brun R, Hauser S, et al. (1999). Cross-regulation of C/EBP alpha and PPAR gamma controls the transcriptional pathway of adipogenesis and insulin sensitivity. Mol. Cell 3: 151-158.

Zhang JX, Ma YX, Wen Y, Xu XJ, et al. (2009). Erythropoietin by PI3 K/Akt signaling pathway inhibition induced by angiotensin $\alpha$ newborn rat cardiac fibroblasts proliferation. Chin. J. Pathophysiol. 25: 293-298.

Zhu RJ, Wu MQ, Li ZJ, Zhang Y, et al. (2013). Hematopoietic recovery following chemotherapy is improved by BADGEinduced inhibition of adipogenesis. Int. J. Hematol. 97: 58-72. 